\title{
$A X Y 3$ encodes a $\alpha$-xylosidase that impacts the structure and accessibility of the hemicellulose xyloglucan in Arabidopsis plant cell walls
}

\author{
Markus Günl • Markus Pauly
}

Received: 19 October 2010/Accepted: 29 November 2010/Published online: 18 December 2010

(C) The Author(s) 2010. This article is published with open access at Springerlink.com

\begin{abstract}
Xyloglucan is the most abundant hemicellulose in the walls of dicots such as Arabidopsis. It is part of the load-bearing structure of a plant cell and its metabolism is thought to play a major role in cell elongation. However, the molecular mechanism by which xyloglucan carries out this and other functions in planta is not well understood. We performed a forward genetic screen utilizing xyloglucan oligosaccharide mass profiling on chemically mutagenized Arabidopsis seedlings to identify mutants with altered xyloglucan structures termed axy-mutants. One of the identified mutants, axy3.1, contains xyloglucan with a higher proportion of non-fucosylated xyloglucan subunits. Mapping revealed that axy3.1 contains a point mutation in XYLOSIDASE1 (XYL1) known to encode for an apoplastic glycoside hydrolase releasing xylosyl residues from xyloglucan oligosaccharides at the non-reducing end. The data support the hypothesis that AXY3/XYL1 is an essential component of the apoplastic xyloglucan degradation machinery and as a result of the lack of function in the various axy3-alleles leads not only to an altered xyloglucan structure but also a xyloglucan that is less tightly associated with other wall components. However, the plant can cope with the excess xyloglucan relatively well as the mutant does not display any visible growth or morphological phenotypes with the notable exception of shorter siliques and reduced fitness. Taken together, these results demonstrate that plant apoplastic hydrolases have a larger impact
\end{abstract}

Electronic supplementary material The online version of this article (doi:10.1007/s00425-010-1330-7) contains supplementary material, which is available to authorized users.

M. Günl · M. Pauly ( $₫)$

Department of Plant and Microbial Biology,

University of California Berkeley, Berkeley, CA, USA

e-mail: mpauly69@berkeley.edu on wall polymer structure and function than previously thought.

Keywords Cell walls $\cdot$ Xyloglucan $\cdot$ Xylosidase . Arabidopsis

\begin{tabular}{|c|c|}
\hline \multicolumn{2}{|l|}{ Abbreviations } \\
\hline Axy & Altered xyloglucan \\
\hline AIR & Alcohol insoluble residue \\
\hline HPAEC & $\begin{array}{l}\text { High-performance anion-exchange } \\
\text { chromatography }\end{array}$ \\
\hline MALDI-TOF & $\begin{array}{l}\text { Matrix-assisted laser desorption/ionization } \\
\text { time-of-flight mass spectrometer }\end{array}$ \\
\hline OLIMP & Oligosaccharide mass profiling \\
\hline oligo & Oligosaccharide \\
\hline TFA & Trifluoroacetic acid \\
\hline XEG & Xyloglucan-specific endoglucanase \\
\hline XyG & Xyloglucan \\
\hline
\end{tabular}

\section{Introduction}

The major hemicellulosic polysaccharide in the primary plant cell wall, i.e., the wall of growing cells, of dicots and non-gramineous monocots is xyloglucan (Hayashi 1989; Scheller and Ulvskov 2010). Xyloglucan (XyG) is also present in the walls of grasses but to a lesser extent (Gibeaut et al. 2005). The structure of XyG is relatively well described. It consists of a $\beta-1,4$ linked glucan chain that is decorated with various heterogeneous side chains. The pattern of XyG substitutions of each backbone glucosyl residue is described using a single letter nomenclature (Fry et al. 1993). The letter $G$ describes an unsubstituted 
backbone $\beta$-D-Glc $p$ residue, while $\mathrm{X}$ denotes a backbone glucose-unit substituted with a xylosyl residue, i.e., a $\alpha$-D-Xyl $p$ - $(1 \rightarrow 6)-\beta$-D-Glcp motif. In many dicots such as Arabidopsis thaliana, the xylosylation pattern is in general regular consisting mainly of XXXG-type units (Zablackis et al. 1995; Vincken et al. 1997). The xylosyl residue can be further substituted at the O-2 position with a $\beta$-D-Gal $p$ residue ( $\mathrm{L}$ side chain). The galactosyl residue in turn is often substituted with an $\alpha$-L-Fuc $p$ residue at the $\mathrm{O}-2$ position (F side chain) and/or with an $O$-acetyl-substituent (underlined $\underline{L}$ side chain, if only substituted with the $O$-acetyl substituent or underlined $\underline{\mathrm{F}}$ side chain, if substituted with both $O$-acetyl- and fucosyl-substituent (Kiefer et al. 1989; Pauly et al. 2001a).

$\mathrm{XyG}$ is synthesized in the Golgi apparatus (Lerouxel et al. 2006) and secreted into the apoplast via exocytosis, where it is thought to form a tight non-covalent association with cellulose microfibrils (Bauer et al. 1973). This cellulose-XyG network is thought to be the load-bearing structure of the cell (Fry 1989). However, once incorporated in the apoplastic network XyG can undergo further enzymatic modifications (Pauly et al. 2001b). Therefore, $\mathrm{XyG}$ is thought to occur in distinct domains within the network (Pauly et al. 1999a). One domain of the polymer is thought to act as microfibril cross-linking tethers that are enzyme accessible. Another domain of the same polymer is tightly associated with the cellulose microfibril via H-bonds and has thus only limited or no accessibility to enzymes. A third domain is thought to be interdispersed within the microfibril making it completely inert to further modification. The main apoplastic enzymes that act on $\mathrm{XyG}$ are endoglucanases cleaving $\mathrm{XyG}$ and generating XyG oligosaccharides (Hayashi et al. 1984), XyG endotransglycosylases (XETs) that cut and religate XyG polymers either involved in remodeling $\mathrm{XyG}$ in the wall or incorporation of newly synthesized XyG (Smith and Fry 1991; Nishitani and Tominaga 1992; Vissenberg et al. 2005) and expansins, proteins that are known to cause cell wall creep (Cosgrove 2005). It is thought that the finely orchestrated action of these enzymes is the major contributor to cell wall expansion thus regulating plant growth (Pauly et al. 2001b). XyG oligosaccharides (oligos) themselves have also been shown to be part of this coordinated wall expansion effort (York et al. 1984; Takeda et al. 2002).

Much of what is known about the function of XyG in planta has been elucidated through the identification and characterization of plant mutants. In addition, these mutants yielded essential information about the molecular machinery of XyG biosynthesis and metabolism (Scheible and Pauly 2004). For example, several Arabidopsis mur mutants altered in their XyG structure were identified through a forward genetic screen based on wall monosaccharide composition (Reiter et al. 1997). MUR1-3 turn out to encode components necessary for XyG biosynthesis; MUR1 a GDP-mannose-2,4-dehydratase responsible for the synthesis of the precursor GDP-L-Fucose (Bonin et al. 1997), MUR2 a XyG: fucosyltransferase (Vanzin et al. 2002), and MUR3 one of the XyG: galactosyltransferases (Madson et al. 2003). All of the mur mutants displayed $\mathrm{XyG}$ structures with altered side chains. In murl, a mutant with $\mathrm{XyG}$ fucosylation level down to $2 \%$ of wild-type levels in aerial parts of the plant, plant dwarfism and a mechanical weakness of the stem tissue was observed (Reiter et al. 1993; Zablackis et al. 1996). However, this phenotypic effect was later attributed to an alteration in the pectic polysaccharide rhamnogalacturonan II and not XyG (O'Neill et al. 2001). Lack of XyG fucosyl-substituents in mur2 and an additional reduction of a specific galactosyl residue in mur3 displayed no different plant growth or morphological phenotype (Perrin et al. 2003; Madson et al. 2003). However, on a cellular level a defect in the organization of the endomembrane/actin system in the cell was shown (Tamura et al. 2005); on a macroscopic level the mutant was found to resist infection in the petiole (Tedman-Jones et al. 2008). Other XyG mutants have been identified through reverse genetic approaches including $\mathrm{XyG}$ : xylosyltransferase mutants. A mutant, the XyG: xylosyltransferase $x x t 5$, showed a root hair phenotype and alterations in primary root morphology (Zabotina et al. 2008). The root hair phenotype was also observed in a $x x t 1 / x x t 2$ double mutant (Cavalier et al. 2008). Hypocotyls of this double mutant had alterations in mechanical properties as they displayed reduced stiffness. Interestingly, this double mutant had a seeming lack of any detectable $\mathrm{XyG}$ in their walls raising an important yet to be answered question; what is the precise function of this major hemicellulose in the wall?

To address this issue we have undertaken a forward genetic screen to identify more mutants with defined altered $\mathrm{XyG}$ structures. This screen was performed on a chemically mutagenized Arabidopsis population and is based on oligosaccharide mass profiling (OLIMP) of XyG (Lerouxel et al. 2002). OLIMP entails the profiling of the $\mathrm{XyG}$ structure released from the wall by the action of a XyG specific hydrolase (XEG; Pauly et al. 1999b) and subsequent analysis of the solubilized $\mathrm{XyG}$ oligos by mass spectrometry. OLIMP is a rapid and sensitive method (Obel et al. 2009) giving semi-quantitative insights into the relative distribution of $\mathrm{XyG}$ side chains. One of the mutants that we identified is a mutant with altered XyG 3.1 (axy3.1), whose identification and characterization we describe here. 


\section{Materials and methods}

Plant material and growth conditions

The axy3.1 mutant was identified by OLIMP from an ethylmethanesulfonate (EMS) induced mutant population of Arabidopsis ecotype Col0 (Berger and Altmann 2000). The two axy3 T-DNA insertional lines were obtained from the GABI-Kat consortium (axy3.2; GABI_749G08) and from the Arabidopsis Biological Resource Center (axy3.3; SAIL_916H10).

Etiolated Arabidopsis (Arabidopsis thaliana) wild type and mutant seedlings were grown on $0.5 \times$ MS-media plates (Murashige and Skoog 1962) containing 1\% sucrose and $1 \%$ agar. Sterilized seeds were placed on plates and stratified in the dark for $2-3$ days at $4^{\circ} \mathrm{C}$ to synchronize germination. After stratification plates were transferred to environmental controlled growth chambers set to $22^{\circ} \mathrm{C}$ and growth was induced by a $6 \mathrm{~h}$ light treatment (130-140 $\mu \mathrm{mol} \mathrm{m} \mathrm{m}^{-2} \mathrm{~s}^{-1}$ light intensity). After light treatment plates were wrapped three times with aluminum foil and grown for a further 4-5 days.

For phenotypic analysis, plants were grown in environmental controlled growth chambers under long day conditions (16 h light $/ 8 \mathrm{~h}$ dark) at $170-190 \mu \mathrm{mol} \mathrm{m}^{-2} \mathrm{~s}^{-1}$ light intensity and $22^{\circ} \mathrm{C}$. Mature siliques were harvested from 6 weeks old plants and digital images of siliques were obtained, the length was measured using ImageJ software. The amount of seeds per siliques was determined on dried siliques from 2-month-old plants.

Rough mapping, complementation, and semi-quantitative RT-PCR

Mutant and wild-type $\mathrm{F}_{2}$ plants generated from a cross of axy3.1 (background ecotype Col0) $\times$ wild type (ecotype Landsberg errecta) were used for rough mapping of axy3.1. A microarray based approach was used to determine Col0 and Landsberg allele frequencies in the mapping population of $\mathrm{F}_{2}$ mutant and wild-type plants as previously described (Borevitz 2006). The mutation in XYL1 was confirmed by gene sequencing.

For genetic complementation of axy3.1, the full-length genomic sequence of At1g68560 (XYL1) was PCR amplified from Col0 wild-type genomic DNA (forward primer: CTGTCATCTTGCACTGCTACAG, reverse primer: CTT GGGAGCTAAAGCCAATG) including a $1.7 \mathrm{~kb}$ sequence upstream of the start codon (promoter region) using Phusion polymerase (Finnzymes). The PCR product was cloned into the $\mathrm{pCR}^{\circledR}$-XL-TOPO ${ }^{\circledR}$ vector (Invitrogen) following the instructions of the manufacturer. This sequence was cloned into the binary plant transformation vector pORE O4 (Coutu et al. 2007) using the Sac I and
Not I restriction sites. Homozygous Arabidopsis axy3.1 mutant plants were transformed by vacuum infiltration (Weigel and Glazebrook 2002) with Agrobacterium tumefaciens GV3101. Homozygous-complemented lines were selected by segregation analysis using the kanamycin resistance marker.

For analyzing XYL1 expression levels in axy3 mutant lines, total RNA was isolated from 14-day-old seedlings using the RNeasy kit (Qiagen) followed by DNase I (Roche) digest, according to the guidelines of the manufacturers. To obtain cDNA $2.5 \mu \mathrm{g}$ RNA was transcribed using M-MLV reverse transcriptase (Invitrogen) following the instructions of the manufacturer. PCR was carried out on $1 \mu \mathrm{l}$ cDNA template with a final primer concentration of $0.5 \mu \mathrm{M}$ and $\mathrm{GoTaq}^{\circledR}$ Green Master Mix (Promega) in $20 \mu \mathrm{l}$ volume. The XYL1 amplicon was located downstream of all axy3 mutations in the last exon of XYL1 (forward primer: TCCGGAAATGAAGCTAGGAA, reverse primer: GCTCCTTCGAGCTAACCTCA). An amplicon in the house-keeping gene ACT3 was amplified in parallel (forward primer: GGTCGTACTACTGGTATTGTGCT, reverse primer: TGACAATTTCACGCTCAGCT). PCR reactions started with initial heating to $94^{\circ} \mathrm{C}$ for $5 \mathrm{~min}$ followed by 30 cycles consisting of $94^{\circ}, 60^{\circ}$, and $72^{\circ} \mathrm{C}$ for $30 \mathrm{~s}$ each and a final step of $72^{\circ} \mathrm{C}$ for $10 \mathrm{~min}$. Gel electrophoresis of PCR products was performed with $4 \%$ agarose gel, and PCR products were stained with ethidium bromide.

\section{OLIMP of XyG}

Essentially, OLIMP was carried out as shown previously (Günl et al. 2010). Briefly, alcohol insoluble residue (AIR) was prepared from approximately ten 5-day-old etiolated Arabidopsis seedlings. Plant tissue was placed into microfuge tubes and immediately snap-frozen in liquid nitrogen and ground in a ball mill (Retsch). The ground material was extracted once with $1 \mathrm{ml} 70 \%$ ethanol followed by an extraction with $1 \mathrm{ml} \mathrm{1:1} \mathrm{chloroform:methanol}$ $(\mathrm{v} / \mathrm{v})$. The supernatants were aspirated after centrifugation (14,000 rpm, $10 \mathrm{~min}$ ). For OLIMP analysis of siliques and the $\mathrm{F}_{2}$ mapping population, AIR was extracted from single mature siliques and from leaves of 2-3 week-old-plants, respectively, using the same procedure.

AIR was digested overnight at $37^{\circ} \mathrm{C}$ with $0.2 \mathrm{U}$ xyloglucan-specific endoglucanase (XEG; Pauly et al. 1999b) in $50 \mu \mathrm{l} 50 \mathrm{mM}$ ammonium formate, $\mathrm{pH}$ 4.5. After XEG digestion the samples were centrifuged and the supernatants, containing the soluble $\mathrm{XyG}$ oligos, were transferred to new microfuge tubes. If necessary, the supernatant was concentrated to increase the oligo concentration. To desalt samples for MALDI-TOF analysis, a $10 \mu \mathrm{l}$ sample was incubated for 15 min with five to ten conditioned BioRex MSZ 501 cation exchange beads. After spotting $2 \mu \mathrm{l}$ matrix 
(2,5-dihydroxybenzoic acid, $10 \mathrm{mg} \mathrm{ml}^{-1}$ in water) onto the MALDI target plate, the plate was dried under vacuum and $2 \mu \mathrm{l}$ desalted sample was added to the dried matrix spot. After 5 min incubation, the MALDI target plate was dried under vacuum. Mass spectrometry was performed on a MALDI-TOF (Shimadzu) set to positive reflectron mode with an acceleration voltage of 20,000 V.

\section{Cell wall extractions}

For neutral sugar composition and high-performance anion-exchange chromatography (HPAEC) analysis, 4-day-old etiolated Arabidopsis seedlings were harvested and freeze-dried (Labconco). After freeze-drying, approximately $50-100 \mathrm{mg}$ etiolated seedlings were transferred to microfuge tubes, frozen in liquid nitrogen and ball milled. The ground material was extracted three times with $1 \mathrm{ml}$ 70\% ethanol and once with $1 \mathrm{ml}$ 1:1 (v/v) chloroform:methanol. After each extraction step, the samples were centrifuged $(14,000 \mathrm{rpm}, 10 \mathrm{~min})$ and the supernatant was aspirated. After extraction the AIR was dried by vacuum centrifugation (Labconco). To aliquot the AIR, extracted material was resuspended in water $\left(10 \mathrm{mg} \mathrm{ml}^{-1}\right.$ ) and $200 \mu \mathrm{l}$ aliquots (representing $2 \mathrm{mg}$ AIR) was transferred to $2 \mathrm{ml}$ screw-capped microfuge tubes (Sarstedt). Samples were dried by vacuum centrifugation.

An overview of sequential cell wall extractions is given in Figure S2. Buffer-soluble cell wall components were extracted for $22 \mathrm{~h}$ with $250 \mu \mathrm{l} 50 \mathrm{mM}$ ammonium formate, $\mathrm{pH} 4.5$, containing $0.01 \%$ sodium azide under constant shaking $(230 \mathrm{rpm})$. After buffer extraction, samples were spun down for $10 \mathrm{~min}$ at $14,000 \mathrm{rpm}$ and $200 \mu \mathrm{l}$ supernatant was transferred to a new tube. The residue was washed with $0.5 \mathrm{ml}$ water followed by a $1 \mathrm{ml}$ water wash. Both washes were combined with the buffer fraction, and dried by vacuum centrifugation.

For extracting $4 \mathrm{M}$ potassium hydroxide soluble polymers from AIR, samples were incubated in $500 \mu \mathrm{l} 4 \mathrm{M}$ potassium hydroxide under constant shaking. After $4 \mathrm{~h}$, samples were spun down for $10 \mathrm{~min}$ at $14,000 \mathrm{rpm}$ and $450 \mu \mathrm{l}$ supernatant was transferred to a new tube. The residues were washed twice with $1 \mathrm{ml}$ water and the supernatants were combined resulting in the $4 \mathrm{M} \mathrm{KOH}$ fraction. The remaining residues were dried by vacuum centrifugation. The $4 \mathrm{M} \mathrm{KOH}$ fraction was neutralized with concentrated hydrochloric acid. For XyG precipitation, ethanol was added to a final concentration of $70 \%$ and the samples were incubated overnight at $4^{\circ} \mathrm{C}$. After precipitation, the samples were spun down $(4,000 \mathrm{rpm}$, $10 \mathrm{~min}, 4^{\circ} \mathrm{C}$ ) and the residues were washed three times with $10 \mathrm{ml}$ ice cold $70 \%$ ethanol and dried by vacuum centrifugation.
Neutral sugar composition and HPAEC analysis of XyG oligos

AIR, buffer, and $4 \mathrm{M} \mathrm{KOH}$ fractions were digested overnight at $37^{\circ} \mathrm{C}$ in $500 \mu 150 \mathrm{mM}$ ammonium formate buffer ( $\mathrm{pH} 4.5$ ) containing $1 \mathrm{U}$ XEG. After digestion, the samples were spun down and $450 \mu \mathrm{l}$ XEG digest was transferred to the new tube. For XEG digestion on AIR, the remaining residue was washed twice with $1 \mathrm{ml}$ water, incubated for $5 \mathrm{~min}$ in boiling water (to inactivate any remaining XEG activity) and the residue was dried by vacuum centrifugation. The residue was used for $4 \mathrm{M} \mathrm{KOH}$ extraction as described above.

The XyG oligo composition was analyzed on an ICS3000 HPAEC system (Dionex) equipped with a CarboPac PA200 column using pulsed amperometric detection (PAD). In order to remove any remaining particles from XEG digests, samples were filtered using a $0.45 \mu \mathrm{m}$ PVDF syringe filter (Millipore) prior to injection in the HPAEC. To elute XyG oligos, a gradient from $100 \mathrm{mM}$ sodium hydroxide to $80 \mathrm{mM}$ sodium acetate in $100 \mathrm{mM}$ sodium hydroxide was run for $15 \mathrm{~min}$ with a flow rate of $0.4 \mathrm{ml} \mathrm{min}^{-1}$. From minute 15 to 25 the column was flushed with $300 \mathrm{mM}$ sodium acetate in $100 \mathrm{mM}$ sodium hydroxide. The column was re-equilibrated from minute 25-33 with $100 \mathrm{mM}$ sodium hydroxide. Quantification of $\mathrm{XyG}$ oligos was based on a standard curve generated from commercially available XXXG (Megazyme).

For monosaccharide composition analysis, cell wall polysaccharides from AIR were hydrolyzed with 2 M TFA (York et al. 1985) or by Saeman hydrolysis (Selvendran et al. 1979). After TFA hydrolysis, the TFA-resistant residue was washed twice with $1 \mathrm{ml}$ water and dried by vacuum centrifugation. Saeman hydrolysis was performed on all residues from cell wall extractions and TFA treatment. Hydrolyzed monosaccharides were converted to their alditol acetates and analyzed by GC as illustrated by Foster et al. (2010).

Immunofluorescence labeling of xyloglucan

Etiolated seedlings were harvested from MS media plates and fixed overnight in phosphate buffered saline solution (PBS; $137 \mathrm{mM}$ sodium chloride, $2.7 \mathrm{mM}$ potassium chloride, $10 \mathrm{mM}$ sodium hydrogen phosphate, $1.76 \mathrm{mM}$ potassium dihydrogen phosphate, $\mathrm{pH} 7.4)$ with $4 \%(\mathrm{v} / \mathrm{v})$ formaldehyde. After fixation, seedlings were rinsed twice with buffer and dehydrated with a graded ethanol series; $25 \%(\mathrm{v} / \mathrm{v})$ ethanol for $3 \mathrm{~h}, 50 \%$ (v/v) ethanol for $3 \mathrm{~h}, 75 \%$ (v/v) ethanol overnight, $100 \%(\mathrm{v} / \mathrm{v})$ ethanol overnight. For handling purposes seedlings were stained with Fast Green ( $5 \mathrm{mg} \mathrm{ml}^{-1}$ in ethanol) for $1 \mathrm{~h}$. To remove excess Fast Green, samples were washed twice in $100 \%$ (v/v) ethanol. 
Seedlings were infiltrated overnight with LR white (Fluka). For embedding, seedlings were transferred to conical embedding capsules (Electron Microscopy Sciences) and $0.5 \mathrm{ml} \mathrm{LR}$ White containing $4 \mu \mathrm{ml}^{-1}$ LR White accelerator (Fluka) was added. Polymerization was carried out at room temperature. Seedlings were cut in $10 \mu \mathrm{m}$ thin sections with a Leica RM2265 microtome using low profile steel blades (Leica) and sections were mounted on glass slides coated with Vectabond (Vector Laboratories).

Sections were incubated for $2 \mathrm{~h}$ with 1:30 dilutions of the primary antibodies CCRC-M1 (Puhlmann et al. 1994) and LM15 (Marcus et al. 2008) in PBS containing 3\% (w/v) fat free milk powder (MPBS). After incubation with the primary antibodies, sections were washed three times in PBS and incubated for $1 \mathrm{~h}$ with 1:100 dilutions of the secondary antibodies (FITC conjugates, Sigma) in MPBS, followed by three washes in PBS. Sections were examined with a Leica DMI6000 B confocal microscope.

\section{Results}

The axy3.1 mutant exhibits an altered xyloglucan composition

Etiolated seedlings of an EMS induced mutagenized Arabidopsis population (Berger and Altmann 2000) were screened by OLIMP. One of the isolated mutants with an "altered XyG" (axy) structure was axy3.1. The mutant was identified because its XyG oligo composition showed a relative decrease in fucosylated $\mathrm{XyG}$ oligos, such as XXFG, to about $20 \%$ of levels found in wild type and a concomitant increase in the non-fucosylated XyG oligos XXXG (increase of 25\%) and XXLG/XLXG (double amount; Fig. 1a). To confirm this structural $X y G$ phenotype absolute quantification of XEG released $\mathrm{XyG}$ oligos was performed by HPAEC-PAD analysis (Fig. 1b). While the relative $\mathrm{XyG}$ oligo composition was confirmed in axy3.1, the absolute amount of fucosylated $\mathrm{XyG}$ oligos in axy3.1 remained almost unchanged but instead the abundance of the oligos XXXG and XXLG was increased about threefold and fivefold compared to wild-type Arabidopsis seedlings, respectively.

\section{AXY3 encodes a XyG: $\alpha$-xylosidase (XYL1)}

For mapping of the responsible mutation of the axy3.1 phenotype, an $\mathrm{F}_{2}$ mapping population of axy3.1 (background Col0) and Landsberg erecta (Ler) was generated and OLIMP was performed on leaf material derived from individual $F_{2}$ plants. Out of 299 plants tested 80 exhibited the axy3 phenotype. This does not deviate significantly from a segregation ratio of $1: 3\left(\chi^{2}=0.492, p=0.01\right)$

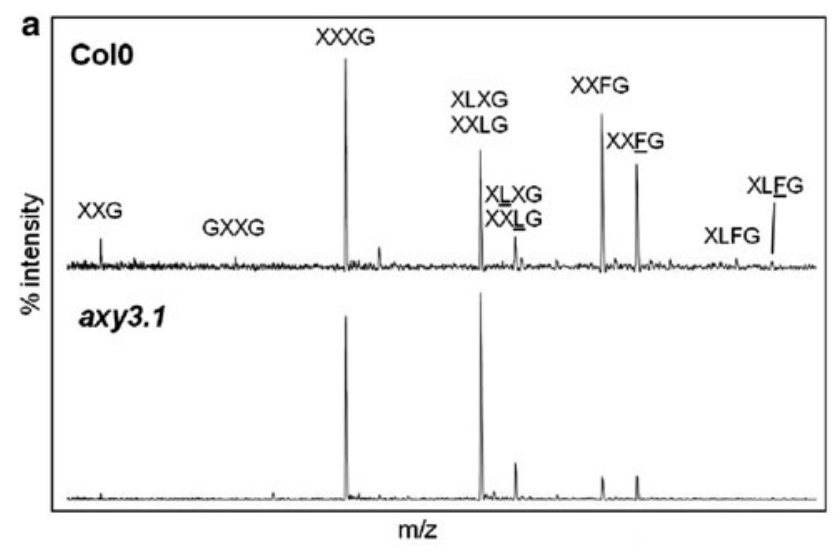

b

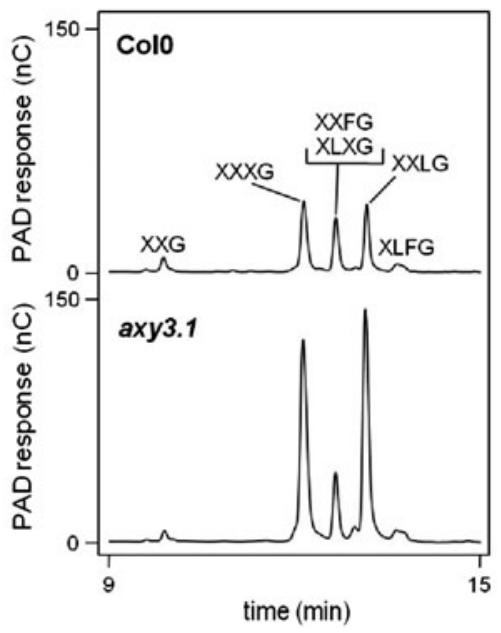

Fig. 1 XyG oligosaccharide composition released by XEG from cell walls. a XyG oligosaccharide mass profile (OLIMP) derived from walls of etiolated seedlings of wild type (Col0) and axy3.1 mutant. XyG oligos structures have been assigned based on $\left[\mathrm{M}+\mathrm{Na}^{+}\right]^{+}$ $\mathrm{XyG}$ structures using the single letter code as described in Fry et al. (1993). b HPAEC-PAD chromatograms of the same XEG released XyG oligosaccharide fraction

indicating that a recessive, single locus mutation was responsible for the observed XyG phenotype. For rough mapping of the mutation pooled genomic DNA from mutant and wild-type $\mathrm{F}_{2}$ plants was analyzed for Col0 and Ler allele frequencies throughout the mutant and wild-type genome using single feature polymorphism (Borevitz 2006). The result indicated a high Col0 background in axy3.1 in a single region on the bottom arm of chromosome 1 (Fig. S1). The region surrounding the highest Col0 allele frequencies comprises 478 genes (At1g67130-At1g71220). This genomic region is also in close proximity to a previously identified OLIMP XyG quantitative trait loci (QTL) between the Arabidopsis ecotypes Bayreuth-0 (Bay0) and Shadara (Sha) (Mouille et al. 2006). This QTL is responsible for an increase of the ratio of XXLG to XXFG, a phenotype that is reminiscent of that of axy3.1. Therefore, there was the possibility that the axy3.1 mutation and the 
QTL in the Bay0/Sha population coincide in the same genetic locus. The genomes of Bay0 and Sha have been sequenced and single nucleotide polymorphisms between these ecotypes have been established and made publicly available (http://www.arabidopsis.org). However, within the axy3.1 rough mapping region more than 5,000 SNPs between Bay0 and Sha are present. Therefore, the list of genes in the rough mapping region was narrowed down by their functional annotation in TAIR9 (http://www.arabi dopsis.org) resulting in 16 candidate genes putatively involved in cell wall metabolism such as glycosyltransferases, expansins, cell wall proteins or glycosylhydrolases. Of these, seven genes had Bay0/Sha SNPs that compared to Col0 would result in missense mutations (Table S1). These candidate genes were sequenced in axy3.1 to identify possible mutations. Indeed, the sequencing of At1g68560 (XYL1) revealed a point mutation in the third exon of the gene, changing the codon GAG (Glu) to AAG (Lys) in amino acid 630 of XYL1. XYL1 exhibits 2 amino acid differences between Bay0 and Sha; Val38 (Bay0) is Leu38 in Sha and Ile48 (Bay0) is Val48 in Sha lending further support to the notion that these mutations in XYL1 might be responsible for the observed XyG QTL between these two ecotypes. XYL1 is member the carbohydrate active enzymes (CAZY) glycoside hydrolase family 31 (GH31) and encodes an apoplastic $\alpha$-xylosidase that is active in vitro against $\mathrm{XyG}$ oligos (Sampedro et al. 2001).

To confirm that the point mutation in $A X Y 3$ is indeed responsible for the observed $\mathrm{XyG}$ compositional phenotype, T-DNA insertional lines for $X Y L 1$ were obtained. For two T-DNA lines, GABI_749G09 (axy3.2) and SAIL_ 916H10 (axy3.3), with insertions located in the second exon and in the second intron, respectively, no XYL1 transcript could be detected in homozygous lines (Fig. 2a, b) demonstrating that those lines can be considered knockouts. OLIMP analysis of etiolated hypocotyls of both T-DNA lines revealed the same $\mathrm{XyG}$ oligo composition as axy3.1 (Fig. 2c), with the characteristic relative decrease in XXFG and concomitant increase in XXLG/XLXG. In addition, a genetic complementation was performed by transforming axy3.1 with a non-mutated wild-type XYL1 driven by its endogenous promoter. OLIMP on the

a

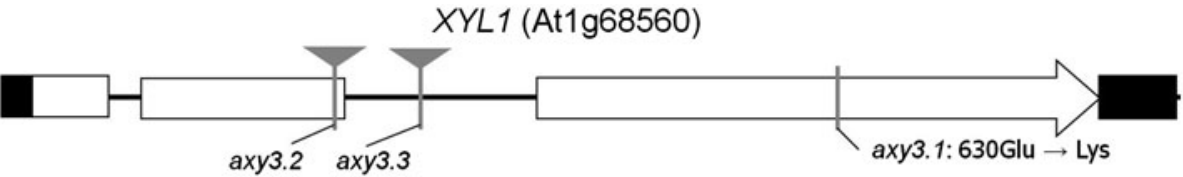

b
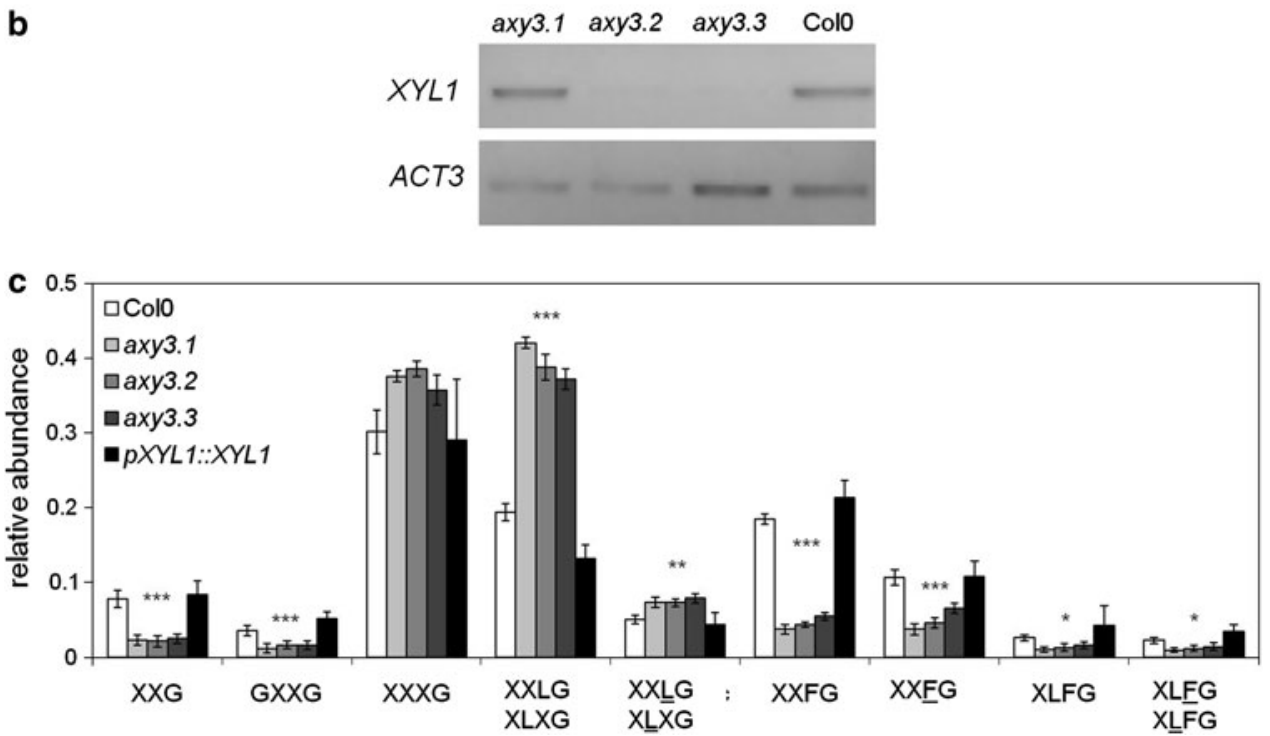

Fig. 2 Analysis of $X Y L 1$ expression in axy3 mutant lines. a XYL1 gene model. XYL1 contains three exons, depicted as white rectangles; non-coding regions are shown as a black line. Black rectangles depict the UTRs. The location of T-DNA insertional lines are indicated by gray triangles, the location of the EMS induced mutation is indicated by a gray vertical line. Location of single nucleotide polymorphism and the resulting amino acid changes between Sha and Bay0 are shown as dotted lines. The EMS induced mutation leads to an amino acid change from glutamic acid (GAG) to lysine (AAG) in amino acid
630. b Semi-quantitative RT-PCR showing expression levels of $X Y L 1$ in axy3 mutants indicating. c OLIMP analysis of XyG of etiolated seedlings from Col0, axy3.1, axy3.2, axy3.3 and a complementation line expressing $X Y L 1$ driven by its native promoter $(p X Y L 1:: X Y L 1)$ in axy3.1. The mean relative abundance $(n=6, \pm \mathrm{SD})$ of $\mathrm{XyG}$ oligos is shown. Asterisks indicate consistent significant changes of all three mutant lines compared to wild type and complementation line $(* p=0.05, * * p=0.01, * * * p=0.001)$ by Student's $t$ test 
transgenic plants indicated a reversal of the $\mathrm{XyG}$ oligo composition back to wild-type (Col0) levels (Fig. 2c). These data demonstrate unambiguously that the mutation of XYL1 in axy3.1 is indeed responsible for the observed $\mathrm{XyG}$ phenotype. Furthermore, the similarity of the $\mathrm{XyG}$ profile in all axy3 alleles suggests that the point mutation in axy3.1 results in a complete loss of activity of XYL1.

axy3 cell walls exhibit a changed $\mathrm{XyG}$ abundance, domain distribution, and oligo composition

Based on the knowledge that the axy3 mutants are impaired in a $\alpha$-xylosidase acting on XyG the OLIMP and HPAEC $\mathrm{XyG}$ compositional data were re-examined (Fig. 1). Consistent with a loss of function of a xylosidase is the reduction in abundance of the XyG oligo GXXG, the primary product of the xylosidase action on XXXG (Fig. 1a). Moreover, the secondary product XXG, which results from the following action of a glucosidase on GXXG (Guillen et al. 1995) is also reduced.

The overall structure of $\mathrm{XyG}$ in the axy3 mutants was investigated in more detail. $\mathrm{XyG}$ is known to occur in the wall in various domains, among them enzyme accessible, cellulose microfibril bound and microfibril internal domains (Pauly et al. 1999a). One can distinguish between these domains by utilizing various extraction techniques. These solubilization techniques were performed and their XyG oligo composition was determined by HPAEC (Fig. $\mathrm{S} 2$ ). First, XyGs that are not integrated into the XyG-cellulose network of the wall were quantified. Such XyG can be extracted from cell walls (alcohol soluble residue (AIR)) with an aqueous buffer, as the polymer is soluble in aqueous solutions but precipitates in $70 \%$ ethanol, the preparation method for AIR (Figs. S2c, 3a). The total amount of this XyG fraction as calculated by the sum of all released XyG oligos and is in Col0 or the complemented mutant relatively low with approx. $1 \mu \mathrm{g} \mathrm{mg}^{-1}$ AIR. However, in the axy3 alleles the amount of the soluble $\mathrm{XyG}$ fraction increased more than fourfold to around $4.5 \mu \mathrm{g} \mathrm{mg}^{-1}$ AIR (Fig. 3a). This increase is mainly due to an increase in the XyG oligos XXXG and XXLG.

A $4 \mathrm{M} \mathrm{KOH}$ extract (KOH fraction) consists of $\mathrm{XyG}$ that are integrated into the wall, specifically in the XyGcellulose network, including $\mathrm{XyG}$ tethers and $\mathrm{XyG}$ that are tightly bound to cellulose but are not entrapped within microfibrils (Figs. S2d, 3b). In the axy3 alleles also this $\mathrm{KOH}$ fraction contains more $\mathrm{XyG}$; an increase of approx. $50 \%$ to about $45 \mu \mathrm{g} \mathrm{mg}^{-1}$ AIR was observed. This increase results exclusively from an increased abundance of XXXG and XXLG but not the fucosylated oligos.

In another extraction, AIR was treated with the xyloglucanase (XEG) releasing only the presumed XyG tethers between microfibrils. XEG is not able to remove $\mathrm{XyG}$ that is hydrogen-bonded to cellulose microfibrils (Fig. S2e). This enzyme accessible portion of $\mathrm{XyG}$ is increased threefold up to $12 \mu \mathrm{g} \mathrm{mg}^{-1}$ AIR in the axy3 alleles (Fig. 3c). Again, mainly the non-fucosylated $\mathrm{XyG}$ oligos contributed to this increase.

The XEG digested AIR was further extracted with $4 \mathrm{M}$ $\mathrm{KOH}$. This sequential $\mathrm{KOH}$ extract should release the remaining XyG domains that remain bound on the surface of cellulose microfibrils but are not located within the microfibrils. Here, also an increase of XyG was observed in
Fig. 3 Quantification of XEG released XyG oligos by HPAEC-PAD from various cell wall fractions as outlined in Figure S2. a Buffer-soluble XyG oligos. b XyG composition of $4 \mathrm{M} \mathrm{KOH}$ extract. $\mathbf{c} \mathrm{XyG}$ composition released by XEG from AIR without prior extraction. d XyG composition of $4 \mathrm{M} \mathrm{KOH}$ extract after previous XEG digestion. Numbers $(1,2,3,4)$ refer to the extraction overview in Fig. S2. The mean quantity ( $n=6$, $\pm \mathrm{SD}$ ) of XyG oligos is shown. Asterisks indicate consistent significant changes of all three mutant lines compared to wild type and complementation line (** $p=0.01$, *** $p=0.001$ ) using pairwise comparisons with Student's $t$ test
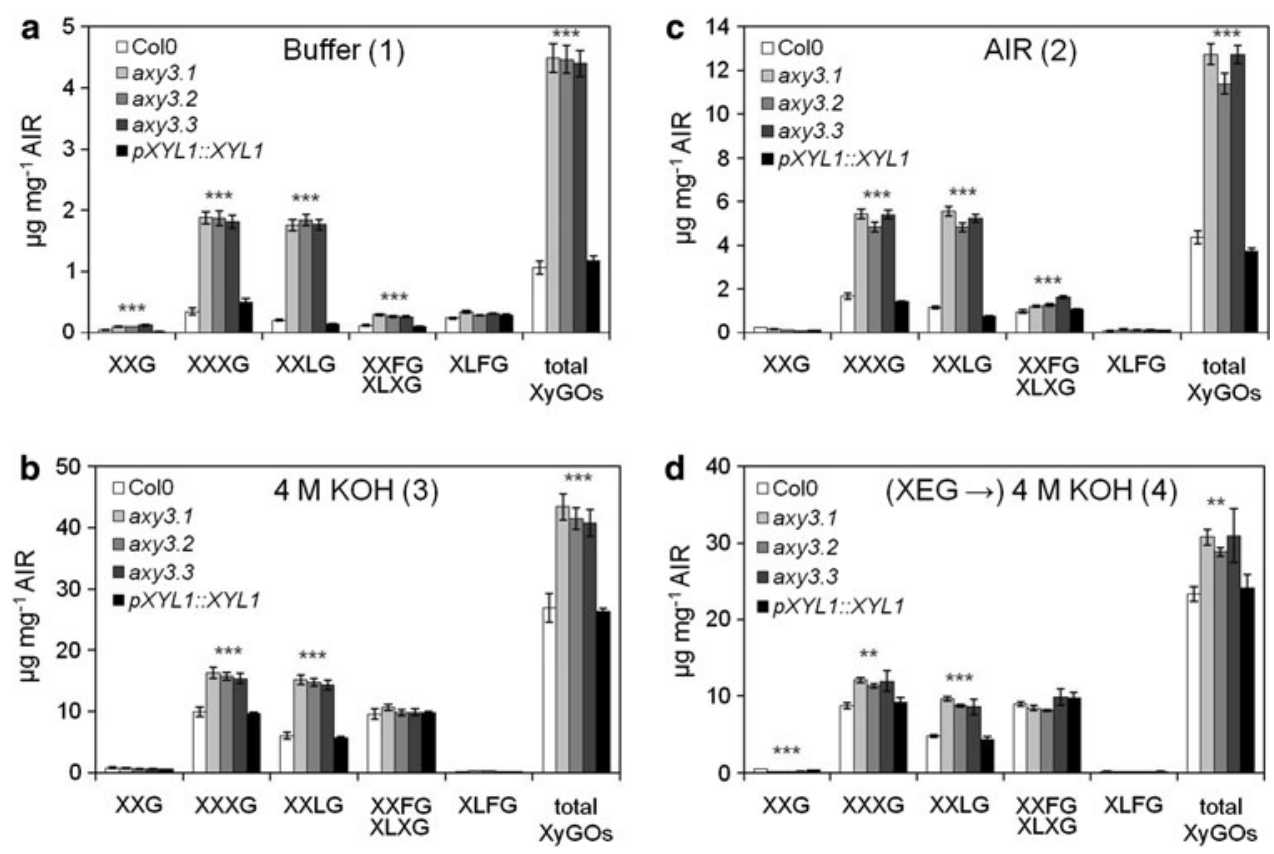
axy3, but to a much lesser extend; only approx. $30 \%$ up $30 \mu \mathrm{g} \mathrm{mg}^{-1}$ AIR (Fig. 3d).

In summary, the $\mathrm{KOH}$ fraction of axy3 mutants contains more $\mathrm{XyG}$ compared to the wild type. Furthermore, the distribution of $\mathrm{XyG}$ domains in axy3 is changed. The buffer-soluble unbound XyG compromises more than $10 \%$ of $\mathrm{XyG}$ (as determined by $\mathrm{KOH}$ extraction) in axy3 mutants, while wild type contains only about $4 \%$ buffersoluble unbound XyGs. Additionally, enzyme accessible $\mathrm{XyG}$ tethers (XEG fraction) represents more than $27 \%$ in axy3 but only about $15 \%$ of the total $\mathrm{XyG}$ in wild type.

Monosaccharide composition and immunofluorescence analyses show little changes in cell wall structure

Structural changes in any other wall polysaccharides were investigated in axy3.1 by monosaccharide composition of AIR derived from etiolated seedlings and AIR after the various XyG extraction procedures (Fig. S2). Two molar TFA treatment of AIR, which hydrolyzes matrix polysaccharides showed no consistent significant changes in monosaccharide composition (Table 1). Furthermore, also the complete hydrolysis of AIR and the TFA-resistant material, which consists mainly of cellulose, by hydrolysis with strong acid and heating using the Saeman procedure (Selvendran et al. 1979) did not show any consistent significant changes in the monosaccharide composition (Table 1).

AIR residues after XyG extraction were completely hydrolyzed by the Saeman procedure and analyzed for monosaccharide composition (Fig. S2c-e, Table 1). A significant increase in the glucose content in the AIR residue after $\mathrm{KOH}$ extraction (Table 1) was observed for all axy3 mutants compared to Col0 and complementation line. When comparing the monosaccharide composition of the AIR and the $\mathrm{KOH}$-fraction residue (hydrolyzed by Saeman procedure) it is evident that the $\mathrm{KOH}$ fraction contains the major portion of XyG as judged by the xylose amounts. In conclusion, no gross changes of the abundance or composition of other wall polymers could be observed in the axy3 mutants.

Besides monosaccharide composition the cell walls of axy3 mutants were also analyzed in situ by immunofluorescent labeling using antibodies specific to XyG (Fig. $\mathrm{S} 3 \mathrm{a}-\mathrm{h})$. However, no differences in the labeling pattern and intensity between mutant and wild-type/complementation line was observed demonstrating that there was no specific tissue effect in axy3.

Mutations in $A X Y 3 / X Y L 1$ lead to reduced silique lengths

In general, plants of all three axy3 alleles did not exhibit any growth or morphological phenotypical differences compared to wild type and complemented plants under the growth conditions used (data not shown) with one exception. All axy3 mutants had significant shorter siliques $(25 \%$ reduction) than both $\mathrm{ColO}$ and complemented mutant (Fig. 4a, b). Moreover, the fitness of axy3 mutant plants was reduced as shown by a decreased number of produced seeds per silique (Fig. 4c). The amount of seeds per silique was reduced from about 60 seeds per silique in Col0 and complemented line to less than 50 seeds in axy3 mutants. This reduction in seed number could be a consequence of reduced silique length. The axy3 XyG oligo phenotype was confirmed on cell wall preparations from mature siliques showing a similar change in oligo distribution as OLIMP on etiolated seedlings (data not shown) indicating that the observed slique/seed number phenotype could be related to the change in XyG structure.

\section{Discussion}

The axy3 mutations cause functional disruption of the apoplastic glycoside hydrolase XYL1

Here we describe the successful identification of $X Y L 1$ mutants using a forward genetic screen facilitating OLIMP. All XYL1 mutants either express a nonfunctional XYL1 protein (axy3.1) or lack detectable full-length XYL1 transcript due to T-DNA insertions (axy3.2 and axy3.3). The EMS mutant axy3.1 exhibits a significant change from an acidic (Glu) to an alkaline (Lys) amino acid residue in position 630, approximately 200 amino acids from the predicted active site of XYL1 (PROSITE; (Sigrist et al. 2010)). This change is likely to lead to protein misfolding and therefore the expression of a nonfunctional enzyme. Furthermore, all axy3.1 phenotypes are rescued to wildtype phenotype by transformation of axy3.1 with XYL1 driven by its endogenous promoter, showing convincingly that the disruption of XYL1 is indeed responsible for the observed axy3 phenotypes.

Previously it had been shown that XYL1 is an apoplastic glycoside hydrolase active on $\mathrm{XyG}$ oligos in vitro (Sampedro et al. 2001). Sampedro et al. were able to detect pentoses-xylose represents the only pentose in XyG of Arabidopsis-released from XyG oligos after incubation with yeast extracts heterolougously expressing XYL1. However, which and how many xylosyl residues are removed from the oligosaccharide remains to be determined and activity towards the XyG polymer has not been tested. Isolation and characterizations of other plant $\alpha$-xylosidases acting on $\mathrm{XyG}$ from pea and nasturtium showed activity towards unsubstituted xylose specifically at the non-reducing end of XyG oligos but not polymeric XyG (O’Neill et al. 1989; Fanutti et al. 1991). Furthermore 
Table 1 Monosaccharide composition of axy3 mutants

\begin{tabular}{|c|c|c|c|c|c|c|c|}
\hline \multicolumn{8}{|c|}{ Monosaccharides' composition $\left(\mu \mathrm{g} \mathrm{mg}^{-1}\right)^{\mathrm{a}}$} \\
\hline Treatment & Rhamnose & Fucose & Arabinose & Xylose & Mannose & Galactose & Glucose \\
\hline \multicolumn{8}{|c|}{ I. TFA hydrolysis of $\mathrm{AIR}^{\mathrm{b}}$} \\
\hline Col0 & $25.8 \pm 1.5$ & $6.5 \pm 0.3$ & $36.0 \pm 2.1$ & $27.2 \pm 1.6$ & $12.7 \pm 0.6$ & $56.8 \pm 3.2$ & $26.8 \pm 1.2$ \\
\hline $\operatorname{axy} 3.1$ & $26.5 \pm 1.5$ & $5.5 \pm 0.3$ & $33.2 \pm 0.6$ & $27.5 \pm 0.6$ & $12.2 \pm 0.7$ & $54.0 \pm 0.9$ & $25.8 \pm 0.6$ \\
\hline $\operatorname{axy} 3.2$ & $25.9 \pm 0.9$ & $5.8 \pm 1.4$ & $34.2 \pm 1.4$ & $29.0 \pm 1.2$ & $12.7 \pm 0.5$ & $58.0 \pm 2.4$ & $28.6 \pm 1.0$ \\
\hline $\operatorname{axy} 3.3$ & $25.5 \pm 1.4$ & $6.0 \pm 1.7$ & $33.6 \pm 1.7$ & $28.4 \pm 1.4$ & $12.4 \pm 0.6$ & $62.4 \pm 3.0$ & $41.0 \pm 2.1$ \\
\hline$p X Y L 1: \because X Y L 1$ & $27.6 \pm 1.8$ & $6.2 \pm 2.1$ & $36.1 \pm 2.1$ & $26.5 \pm 1.7$ & $13.3 \pm 1.0$ & $57.8 \pm 3.5$ & $29.5 \pm 1.9$ \\
\hline \multicolumn{8}{|c|}{ II. Saeman hydrolysis of residue after TFA hydrolysis ${ }^{\mathrm{b}}$} \\
\hline $\mathrm{Col0}$ & $0.4 \pm 0.1$ & ND & ND & $2.3 \pm 0.2$ & $7.6 \pm 0.1$ & $0.7 \pm 0.1$ & $163.9 \pm 7.2$ \\
\hline $\operatorname{axy} 3.1$ & $0.5 \pm 0.0$ & ND & ND & $2.1 \pm 0.3$ & $7.5 \pm 0.4$ & $0.7 \pm 0.1$ & $166.5 \pm 6.0$ \\
\hline $\operatorname{axy} 3.2$ & $0.4 \pm 0.0$ & ND & ND & $1.9 \pm 0.2$ & $7.3 \pm 0.5$ & $0.4 \pm 0.0$ & $176.6 \pm 5.9$ \\
\hline $\operatorname{axy} 3.3$ & $0.4 \pm 0.0$ & ND & ND & $1.8 \pm 0.3$ & $7.3 \pm 0.6$ & $0.5 \pm 0.1$ & $162.5 \pm 10.0$ \\
\hline$p X Y L 1: \because X Y L 1$ & $0.4 \pm 0.0$ & ND & ND & $2.5 \pm 0.2$ & $8.4 \pm 0.3$ & $0.4 \pm 0.1$ & $183.5 \pm 8.0$ \\
\hline \multicolumn{8}{|c|}{ III. Saeman hydrolysis of $\mathrm{AIR}^{\mathrm{b}}$} \\
\hline Col0 & $13.5 \pm 1.9$ & $4.1 \pm 0.3$ & $28.1 \pm 3.0$ & $19.8 \pm 2.0$ & $17.8 \pm 1.4$ & $64.0 \pm 6.4$ & $176.5 \pm 18.1$ \\
\hline $\operatorname{axy} 3.1$ & $12.0 \pm 0.6$ & $3.6 \pm 0.3$ & $26.7 \pm 3.3$ & $19.2 \pm 2.8$ & $16.3 \pm 0.9$ & $52.7 \pm 1.3$ & $183.6 \pm 4.3$ \\
\hline $\operatorname{axy} 3.2$ & $12.2 \pm 0.1$ & $3.6 \pm 0.3$ & $27.7 \pm 0.4$ & $19.4 \pm 2.8$ & $16.7 \pm 0.2$ & $56.1 \pm 1.2$ & $186.8 \pm 2.5$ \\
\hline $\operatorname{axy} 3.3$ & $11.2 \pm 1.3$ & $4.1 \pm 0.4$ & $28.8 \pm 2.8$ & $22.1 \pm 3.0$ & $17.3 \pm 1.1$ & $60.0 \pm 4.2$ & $180.0 \pm 11.7$ \\
\hline$p X Y L 1:: X Y L 1$ & $13.7 \pm 1.5$ & $4.1 \pm 0.5$ & $30.6 \pm 3.8$ & $19.2 \pm 2.7$ & $18.5 \pm 1.5$ & $68.4 \pm 6.9$ & $178.7 \pm 17.6$ \\
\hline \multicolumn{8}{|c|}{ IV. Saeman hydrolysis of residue after buffer extraction ${ }^{\mathrm{b}}$} \\
\hline Col0 & $10.6 \pm 0.8$ & $3.7 \pm 0.3$ & $23.3 \pm 2.8$ & $17.5 \pm 2.6$ & $17.3 \pm 1.3$ & $48.0 \pm 4.6$ & $166.1 \pm 12.5$ \\
\hline $\operatorname{axy} 3.1$ & $8.7 \pm 0.8$ & $2.9 \pm 0.1$ & $20.4 \pm 3.0$ & $15.9 \pm 2.8$ & $14.7 \pm 1.1$ & $42.9 \pm 4.8$ & $177.0 \pm 18.2$ \\
\hline $\operatorname{axy} 3.2$ & $10.1 \pm 1.6$ & $3.1 \pm 0.5$ & $21.7 \pm 3.5$ & $16.1 \pm 2.9$ & $16.0 \pm 2.0$ & $45.8 \pm 6.6$ & $164.0 \pm 23.2$ \\
\hline $\operatorname{axy} 3.3$ & $8.6 \pm 1.0$ & $3.3 \pm 0.4$ & $20.5 \pm 2.2$ & $16.0 \pm 2.2$ & $15.3 \pm 1.4$ & $38.4 \pm 3.6$ & $159.6 \pm 14.5$ \\
\hline$p X Y L 1: \because X Y L 1$ & $9.6 \pm 1.4$ & $3.5 \pm 0.5$ & $22.8 \pm 3.4$ & $14.5 \pm 2.4$ & $15.4 \pm 1.8$ & $47.1 \pm 6.2$ & $153.2 \pm 20.8$ \\
\hline \multicolumn{8}{|c|}{ V. Saeman hydrolysis of residue after $4 \mathrm{M} \mathrm{KOH}$ extraction ${ }^{\mathrm{b}}$} \\
\hline Col0 & $5.9 \pm 0.1$ & $1.1 \pm 0.2$ & $13.7 \pm 2.2$ & $4.0 \pm 0.9$ & $5.4 \pm 0.4$ & $42.0 \pm 2.0$ & $137.2 \pm 4.7$ \\
\hline axy3.1 & $6.2 \pm 0.8$ & $1.0 \pm 0.0$ & $13.4 \pm 2.1$ & $3.7 \pm 0.5$ & $5.6 \pm 0.4$ & $32.4 \pm 2.8$ & $152.3 \pm 9.7 *$ \\
\hline $\operatorname{axy} 3.2$ & $6.5 \pm 0.5$ & $1.0 \pm 0.2$ & $13.7 \pm 1.3$ & $3.4 \pm 0.7$ & $5.8 \pm 0.6$ & $36.9 \pm 0.6$ & $149.3 \pm 7.0 *$ \\
\hline axy3.3 & $6.5 \pm 0.6$ & $1.2 \pm 0.2$ & $15.0 \pm 1.8$ & $4.3 \pm 0.9$ & $6.7 \pm 0.7$ & $40.6 \pm 1.8$ & $154.2 \pm 2.1 *$ \\
\hline$p X Y L 1: \because X Y L 1$ & $6.2 \pm 0.6$ & $1.2 \pm 0.2$ & $14.3 \pm 1.5$ & $4.4 \pm 1.0$ & $6.0 \pm 0.5$ & $31.4 \pm 0.6$ & $141.4 \pm 1.8$ \\
\hline \multicolumn{8}{|c|}{ VI. Saeman hydrolysis of residue after XEG digestion of AIR followed by $4 \mathrm{M} \mathrm{KOH}$ extraction ${ }^{\mathrm{b}}$} \\
\hline $\mathrm{Col}$ & $7.0 \pm 0.6$ & $1.1 \pm 0.2$ & $13.3 \pm 2.3$ & $4.4 \pm 1.2$ & $6.5 \pm 0.6$ & $25.6 \pm 1.9$ & $164.2 \pm 7.9$ \\
\hline $\operatorname{axy} 3.1$ & $5.3 \pm 0.6$ & $1.1 \pm 0.2$ & $9.5 \pm 1.3$ & $3.2 \pm 0.2$ & $5.8 \pm 0.6$ & $18.1 \pm 1.8$ & $150.7 \pm 7.9$ \\
\hline $\operatorname{axy} 3.2$ & $5.9 \pm 0.5$ & $0.9 \pm 0.1$ & $10.0 \pm 1.0$ & $3.4 \pm 0.5$ & $6.4 \pm 0.3$ & $20.9 \pm 0.9$ & $159.8 \pm 5.1$ \\
\hline $\operatorname{axy} 3.3$ & $5.6 \pm 0.5$ & $0.9 \pm 0.1$ & $10.0 \pm 0.8$ & $3.2 \pm 0.6$ & $7.0 \pm 0.5$ & $22.5 \pm 1.4$ & $162.2 \pm 5.7$ \\
\hline$p X Y L 1: \because X Y L 1$ & $5.6 \pm 0.4$ & $0.9 \pm 0.1$ & $9.5 \pm 0.8$ & $3.3 \pm 0.6$ & $7.0 \pm 0.5$ & $20.3 \pm 0.5$ & $161.9 \pm 8.2$ \\
\hline
\end{tabular}

${ }^{a}$ The mean value of 4-6 replicates ( $\pm \mathrm{SD}$ ) is shown. Asterisks indicate consistent significant differences (Student's $t$ test, $p=0.05$ ) for axy3 mutants compared to Col0 and complemented axy3.1 line. ND not detected

${ }^{\mathrm{b}}$ Roman numerals refer to the extraction scheme in Fig. S2

in vitro studies have shown that the degree of Arabidopsis XYL1 phosphorylation is important for its activity (Kaida et al. 2010). Kaida et al. also showed that transgenic tobacco cells overexpressing tobacco purple acid phospphatase (NtPAP12) exihibit reduced $\alpha$-xylosidase activity. XYL1 is member of the carbohydrate active enzyme (CAZy) glycoside hydrolase family 31 (GH31) that comprises five Arabidopsis proteins. Its closest Arabidopsis homolog, At3g45940, is not expressed and likely to be pseudogene (Sampedro et al. 2010). Two other Arabidopsis GH31 proteins have been assigned as $\alpha$-glucosidases due to their homology to mammalian and fungal $\alpha$-glucosidases (Monroe et al. 1999). Besides XYL1, none of these enzyme activities has been studied yet. Hence, a lot remains to be 

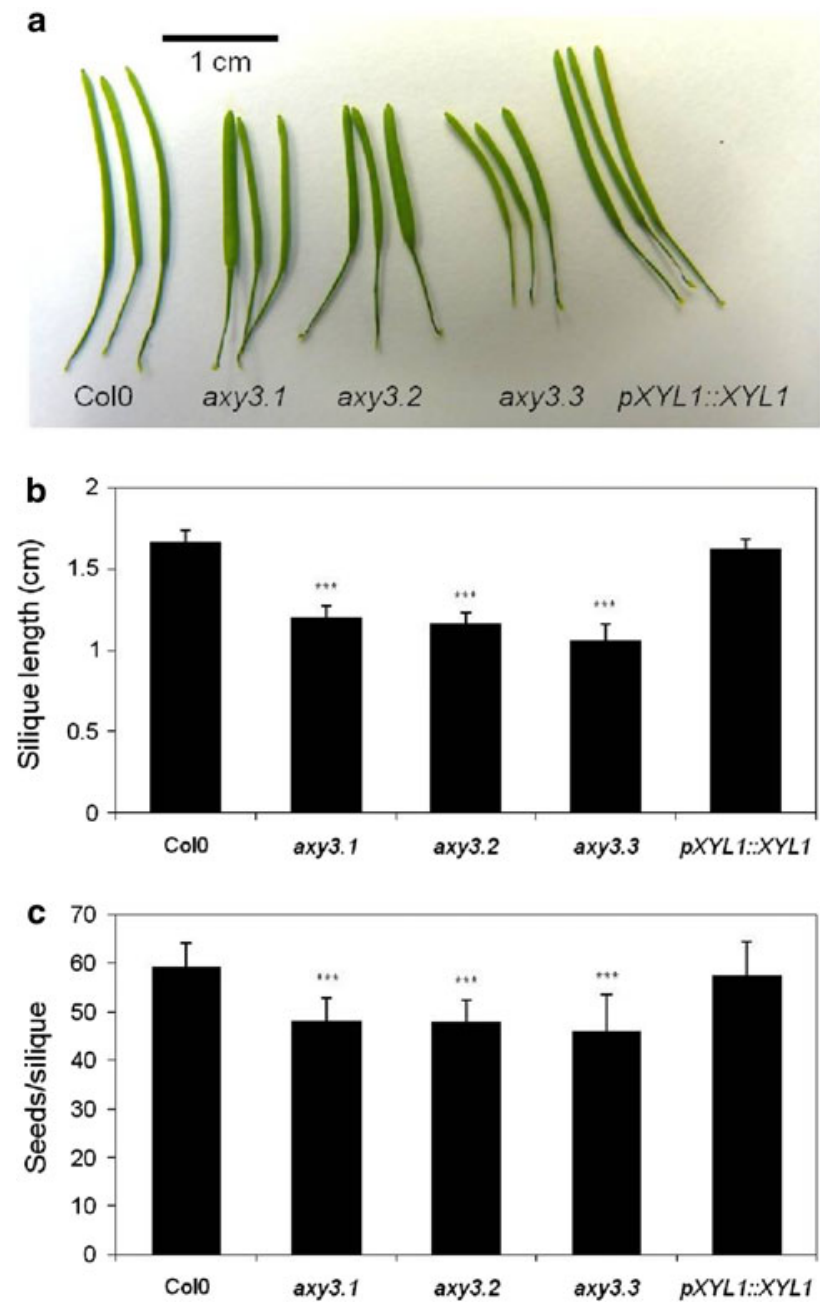

Fig. 4 Silique phenotype in axy3 mutants. a Mature siliques of 6 weeks' old plants from Col0, axy3.1, axy3.2, axy3.3 and complemented axy3.1 line (pXYL1::XYL1). b Average silique length $(n=10-12, \pm \mathrm{SD})$ of mature siliques from 6 weeks old plants. c Average number of seeds per silique $(n=24, \pm \mathrm{SD})$ of siliques from 2-month-old plants. *** Indicates significant differences between mutant and wild-type/complemented axy3.1 line $(p=0.001)$

learnt about the specific activity of this class of plant proteins.

Mutations of XYL1 result in change in xyloglucan structure and concomitant extractability

HPAEC-PAD analyses of XyG oligos compositions of XyGs extracted by $4 \mathrm{M} \mathrm{KOH}$ from axy3 mutants show about $50 \%$ more extractable $\mathrm{XyG}$ than wild type and complementation line (Fig. 3b). For complete XyG degradation at least four enzyme activities are needed; $\alpha$-fucosidase, $\beta$-galactosidase, $\alpha$-xylosidase and $\beta$-glucosidase activity. In Arabidopsis, $\alpha$-xylosidase activity on XyG is likely to be encoded by a single gene (Sampedro et al. 2010). It has been demonstrated that in the Arabidopsis knock-out alleles of $A X Y 3 / X Y L 1, x y l 1-1$ and $x y l 1-2 / a x y 3-2$, $\alpha$-xylosidase activity is not detectable anymore in leaf protein extracts, when tested against the oligosaccharide XXXG (Sampedro et al. 2010). These results demonstrate that AXY3/XYL1 represent the only active xylosidase in Arabidopsis in this tissue. However, $\mathrm{XyG}$ can still be partially modified through the action of the fucosidase and galactosidase in axy3. The glucosidase, which removes backbone glucosyl residues, will probably not act unless the xylosyl-substituents have been removed (Koyama et al. 1983). As a result, one would expect essentially XyG made out of XXXG units. A higher abundance of these oligos is indeed observed in axy3. Interestingly, there is also a higher proportion and absolute abundance of the XXLG oligo in axy3 XyG in the wall. The data suggests that the $\beta$-galactosidase that removes the galactosyl residue is also dependent on a previous $\alpha$-xylosidase action, and so the order of hydrolytic events for such an oligosaccharide would be XXLG $\rightarrow$ GXLG $\rightarrow$ GXXG $\rightarrow$ XXG rather than XXLG $\rightarrow$ XXXG $\rightarrow$ GXXG $\rightarrow$ XXG. However, this observation needs to be further investigated, but it seems to indicate a complex order and regulation of the $\mathrm{XyG}$ hydrolytic machinery. Sampedro et al. 2010 reported a substantial decrease of the fucosylated XyG oligos in the $x y l 1$-mutants up to $50 \%$. However, these results were obtained by mass spectrometric analyses. A quantitative analysis of the XyG oligo composition by HPAEC as reported here did not corroborate these results, indicating that the absolute amount of fucosylated XyG oligos remain constant in the wall.

Digestion of AIR with XEG releases specifically oligos from enzyme accessible XyGs. As expected, due to the activity of the remaining glycoside hydrolases the abundance of XXXG and XXLG in the enzyme accessible XyG domain is particularly high in axy3 (Fig. 3c). On the other hand, extraction of the remaining XyG after XEG digestion (representing the enzyme inaccessible $\mathrm{XyG}$ ) still showed an increase in XXXG and XXLG (Fig. 3d). However, this increase is much less pronounced in the mutants. A possible explanation for this observation could be that there is a rearrangement of $\mathrm{XyG}$ within the cellulose/XyG network from enzyme accessible to microfibril bound $\mathrm{XyG}$ shifting the axy3 xyloglucan phenotype also to the enzyme inaccessible xyloglucan domain. Besides the compositional changes in $\mathrm{XyG}$ structure discussed above it was also shown that some of the XyG in XYL1 mutants is not integrated into the cell wall network (Fig. 3a). This fraction makes up more than $10 \%$ of total extractable XyG in the mutant but only around $4 \%$ in wild type. Similar results have been found in a previous study that analyzed transgenic tobacco cell cultures overexpressing the phosphatase NtPAP12. Higher amounts of total xyloglucan as well as $\mathrm{XyG}$ oligos were found in the cell culture media of 
transgenic plants compared to wild type, likely due to reduced activity of apoplastic glycosidases (Kaida et al. 2010). Also, Sampedro et al. (2010) observed XyG oligos secreted into the media when growing XYL1 Arabidopsis mutant lines in liquid culture. Whether and to what extent any $\mathrm{XyG}$ polymer is secreted into the medium was not investigated in that study. Due to a lack of hydrolysis by glycosidases $\mathrm{XyG}$ probably occurs in these walls in excess and it is possible that cellulose binding sites are already completely occupied resulting in this buffer-soluble fraction. It is interesting to note that in suspension cell cultures a large portion of $\mathrm{XyG}$ is sloughed off into the medium (Pauly et al. 2001a), perhaps again due to the lack of cellulose binding sites. Although the specific interaction between XyG and cellulose is not completely understood, $\mathrm{XyG}$ side chain variability, as observed in axy3, seems to have little effect on its binding capacity to cellulose (discussed in Zhou et al. (2007)). Furthermore, it has been shown that the degree of $\mathrm{XyG}$ substitution and in particular the level of xylosylation could be an important feature for integration of $\mathrm{XyG}$ into the cell wall network by wall modifying enzymes such as xyloglucan endotransglycosylases (Guillen et al. 1995, Steele and Fry 2000). Due to the knock-out of XYL1 in axy3 mutants the degree of XyG xylosylation is not modified in the apoplast and while endoglucanases would still be able to hydrolyze XyG transferases might not be able to reconnect non-modified oligosaccharides leading to an increased amount of unbound XyG. Despite the described increase in extractable $\mathrm{XyG}$, in situ antibody analysis of $\mathrm{XyG}$ showed no differences between axy3 mutants and wild-type/complementation line (Fig. S3a-h). Immunofluorescence labeling is sensitive to conformational changes in the polymer, which could expose or obscure epitopes, making them more or less accessible for antibodies. Masking of epitopes by other cell wall polymers plays an equally important role, it was found that homogalacturonan masks the LM15 epitope in pea and tobacco cells (Marcus et al. 2008). This masking effect could be more pronounced in axy3, making differences in the abundance of epitopes less detectable. In this study antibody labeling was carried out exclusively on a tissue close to the apical hook of etiolated seedlings, no other tissue has been tested. Potentially, the axy3 $\mathrm{XyG}$ phenotype could be less pronounced in this tissue.

Besides xyloglucan in situ analysis monosaccharide composition analysis of AIR and AIR residues after various XyG extractions showed also only little change in sugar composition (Table 1). If the xylose level is taken as a measurement of $\mathrm{XyG}$ content, it is clear that the mutant does not have an overall higher content of XyG (Table 1, Treatment III), corroborating the immunolabeling results mentioned above. The only significant consistent difference observed in the overall cell wall analyses is an increase in the remaining glucose content of AIR after treatment with $4 \mathrm{M}$ potassium hydroxide (Table 1, Treatment $\mathrm{V}$ ). Since the xylose content of the remaining residue is equal before and after $\mathrm{KOH}$ treatment in wild type and mutant the glucose differential does not represent XyG but rather glucans such as amorphous cellulose-chains, which are apparently more solubilized in the wild type than in the axy3 mutants with $\mathrm{KOH}$. Reasons for this could be a change in crystalinity of the cellulose due to the altered XyG structure, differences in the abundance of bound XyG to cellulosic glucan chains and thus occupation of cellulose binding sites, and/or stronger cross-linking of cellulose by $\mathrm{XyG}$ in the mutant making the cellulose/XyG network in the mutant tighter. However the difference in the AIR residue that was first treated with the enzyme XEG and then extracted by potassium hydroxide (Table 1, Treatment VI). One explanation for this result is that XEG solubilizes in particular the enzyme accessible $\mathrm{XyG}$ domain that acts as spacer between cellulose microfibrils. Removing the spacers enzymatically could result in collapsing the cell walls and in a more tightly packed cellulose/XyG network, which is then more recalcitrant to $\mathrm{KOH}$ solubility in the mutant as well as the wild type.

$X Y L 1$ is important for proper silique elongation

XYL1 promoter driven $\beta$-glucuronidase expression (Sampedro et al. 2010) as well as electronic expression analysis using the eFP-Browser (Winter et al. 2007) showed that XYL1 is expressed throughout all major developmental stages and tissues. Furthermore, the axy3 OLIMP phenotype has been found in all tissues tested (such as etiolated seedlings as well as leaves and siliques; data not shown). However, the only clear and consistent change in plant morphology was reduced silique length (Fig. 4). Cell expansion-which is mainly responsible for longitudinal growth during silique development (discussed in Louvet et al. (2006)) — entails major changes to the plant cell wall involving also XyG modifying enzymes (Osato et al. 2006). Therefore, altered $\mathrm{XyG}$ metabolism in axy3 could potentially result in reduced silique length. Another reason for a decrease in silique length could be a reduction in seed production as also observed in axy3 (Fig. 4) due to a reduced pollen transmission rate. This has been demonstrated for other short silique mutants (Grini et al. 2009; Guan et al. 2008). Future research will be necessary to elucidate the causal relationship of the silique phenotype to the altered XyG structure. Besides silique length Sampedro et al. (2010) observed that siliques from XYL1 mutant plants are also wider while sepals are shorter than in wild type and a xyll allele in the Wassilewskija background showed both a change in the ratio of leaf length to leaf width as well as a decrease in trichome branching. 
Acknowledgments The authors would like to thank Kirk Schnorr, Novozymes, Bagsvaerd, Denmark for providing XEG. Josh Hazelwood, JBEI, Emeryville is thanked for the prerelease of the Bay0 and Sha sequence data and Alex Schultink, Pauly lab, UC Berkeley, for help with the Bay0 and Sha SNP analysis.

Open Access This article is distributed under the terms of the Creative Commons Attribution Noncommercial License which permits any noncommercial use, distribution, and reproduction in any medium, provided the original author(s) and source are credited.

\section{References}

Bauer WD, Talmadge KW, Keegstra K, Albersheim P (1973) Structure of plant-cell walls: II. Hemicellulose of walls of suspensioncultured sycamore cells. Plant Physiol 51(1):174-187

Berger D, Altmann T (2000) A subtilisin-like serine protease involved in the regulation of stomatal density and distribution in Arabidopsis thaliana. Genes Dev 14(9):1119-1131

Bonin CP, Potter I, Vanzin GF, Reiter WD (1997) The MUR1 gene of Arabidopsis thaliana encodes an isoform of GDP-D-mannose-4, 6-dehydratase, catalyzing the first step in the de novo synthesis of GDP-L-fucose. Proc Natl Acad Sci USA 94(5):2085-2090

Borevitz J (2006) Genotyping and mapping with high-density oligonucleotide arrays. In: Salinas J, Sanchez-Serrano JJ (eds) Arabidopsis protocols, vol 323. Methods in molecular biology, 2 edn. Humana Press Inc., Totowa, pp 137-145

Cavalier DM, Lerouxel O, Neumetzler L, Yamauchi K, Reinecke A, Freshour G, Zabotina OA, Hahn MG, Burgert I, Pauly M, Raikhel NV, Keegstra K (2008) Disrupting two Arabidopsis thaliana xylosyltransferase genes results in plants deficient in xyloglucan, a major primary cell wall component. Plant Cell 20(6):1519-1537

Cosgrove DJ (2005) Growth of the plant cell wall. Nat Rev Mol Cell Biol 6(11):850-861

Coutu C, Brandle J, Brown D, Brown K, Miki B, Simmonds J, Hegedus DD (2007) pORE: a modular binary vector series suited for both monocot and dicot plant transformation. Transgenic Res 16(6):771-781

Fanutti C, Gidley MJ, Reid JSG (1991) A xyloglucan-oligosaccharidespecific $\alpha$-D-xylosidase or exo-oligoxyloglucan-a-xylohydrolase from germinated nasturtium (Tropaeolum majus L.) seedspurification, properties and its interaction with xyloglucanspecific endo-( $1 \rightarrow 4)$ - $\beta$-glucanase and other hydrolases during storage-xyloglucan mobilization. Planta 184(1):137-147

Foster CE, Martin TM, Pauly M (2010) Comprehensive compositional analysis of plant cell walls (Lignocellulosic biomass) Part II: carbohydrates. J Vis Exp (37). doi:10.3791/1837

Fry SC (1989) The structure and functions of xyloglucan. J Exp Bot 40(210):1-11

Fry SC, York WS, Albersheim P, Darvill A, Hayashi T, Joseleau JP, Kato Y, Lorences EP, Maclachlan GA, McNeil M, Mort AJ, Reid JSG, Seitz HU, Selvendran RR, Voragen AGJ, White AR (1993) An unambiguous nomenclature for xyloglucan-derived oligosaccharides. Physiol Plant 89(1):1-3

Gibeaut DM, Pauly M, Bacic A, Fincher GB (2005) Changes in cell wall polysaccharides in developing barley (Hordeum vulgare) coleoptiles. Planta 221(5):729-738

Grini PE, Thorstensen T, Alm V, Vizcay-Barrena G, Windju SS, Jorstad TS, Wilson ZA, Aalen RB (2009) The ASH1 HOMOLOG 2 (ASHH2) histone $\mathrm{H} 3$ methyltransferase is required for ovule and anther development in Arabidopsis. PLoS One 4(11):e7817
Guan YF, Huang XY, Zhu J, Gao JF, Zhang HX, Yang ZN (2008) RUPTURED POLLEN GRAIN1, a member of the MtN3/saliva gene family, is crucial for exine pattern formation and cell integrity of microspores in Arabidopsis. Plant Physiol 147(2):852-863

Guillen R, York WS, Pauly M, An JH, Impallomeni G, Albersheim P, Darvill AG (1995) Metabolism of xyloglucan generates xylosedeficient oligosaccharide subunits of this polysaccharide in etiolated peas. Carbohydr Res 277(2):291-311

Günl M, Gille S, Pauly M (2010) OLIgo Mass Profiling (OLIMP) of extracellular polysaccharides. J Vis Exp 40. doi:10.3791/2046

Hayashi T (1989) Xyloglucans in the primary cell wall. Annu Rev Plant Physiol Plant Mol Biol 40:139-168

Hayashi T, Wong YS, Maclachlan G (1984) Pea xyloglucans and cellulose: II. Hydrolysis by pea endo-1,4- $\beta$-glucanases. Plant Physiol 75(3):605-610

Kaida R, Serada S, Norioka N, Norioka S, Neumetzler L, Pauly M, Sampedro J, Zarra I, Hayashi T, Kaneko TS (2010) Potential role for purple acid phosphatase in the dephosphorylation of wall proteins in tobacco cells. Plant Physiol 153(2):603-610

Kiefer LL, York WS, Darvill AG, Albersheim P (1989) Xyloglucan isolated from suspension-cultured sycamore cell-walls is $O$-acetylated Phytochemistry 28(8):2105-2107

Koyama T, Hayashi T, Kato Y, Matsuda K (1983) Degradtion of xyloglucan by wall-bound enzymes from soybean tissue: II. Degradation of the fragement heptasaccharide from xyloglucan and the characteristic action pattern of the $\alpha$-D-xylosidase in the enzyme-system. Plant Cell Physiol 24(2):155-162

Lerouxel O, Choo TS, Séveno M, Usadel B, Faye L, Lerouge P, Pauly M (2002) Rapid structural phenotyping of plant cell wall mutants by enzymatic oligosaccharide fingerprinting. Plant Physiol 130(4):1754-1763

Lerouxel O, Cavalier DM, Liepman AH, Keegstra K (2006) Biosynthesis of plant cell wall polysaccharides-a complex process. Curr Opin Plant Biol 9(6):621-630

Louvet R, Cavel E, Gutierrez L, Guénin S, Roger D, Gillet F, Guerineau F, Pelloux J (2006) Comprehensive expression profiling of the pectin methylesterase gene family during silique development in Arabidopsis thaliana. Planta 224(4):782-791

Madson M, Dunand C, Li XM, Verma R, Vanzin GF, Calplan J, Shoue DA, Carpita NC, Reiter WD (2003) The MUR3 gene of Arabidopsis encodes a xyloglucan galactosyltransferase that is evolutionarily related to animal exostosins. Plant Cell 15(7): $1662-1670$

Marcus SE, Verhertbruggen Y, Herve C, Ordaz-Ortiz JJ, Farkas V, Pedersen HL, Willats WGT, Knox JP (2008) Pectic homogalacturonan masks abundant sets of xyloglucan epitopes in plant cell walls. BMC Plant Biol 8:60

Monroe JD, Gough CM, Chandler LE, Loch CM, Ferrante JE, Wright PW (1999) Structure, properties, and tissue localization of apoplastic $\alpha$-glucosidase in crucifers. Plant Physiol 119(2): 385-397

Mouille G, Witucka-Wall H, Bruyant M-P, Loudet O, Pelletier S, Rihouey C, Lerouxel O, Lerouge P, Höfte H, Pauly M (2006) Quantitative trait loci analysis of primary cell wall composition in Arabidopsis. Plant Physiol 141(3):1035-1044

Murashige T, Skoog F (1962) A revised medium for rapid growth and bioassays with tobacco tissue cultures. Physiol Plant 15(3): 473-497

Nishitani K, Tominaga R (1992) Endoxyloglucan transferase, a novel class of glycosyltransferase that catalyzes transfer of a segment of xyloglucan molecule to another xyloglucan molecule. J Biol Chem 267(29):21058-21064

O'Neill RA, Albersheim P, Darvill AG (1989) Purifcation and characterization of a xyloglucan oligosaccharide-specific xylosidase from pea seedlings. J Biol Chem 264(34):20430-20437 
O’Neill MA, Eberhard S, Albersheim P, Darvill AG (2001) Requirement of borate cross-linking of cell wall rhamnogalacturonan II for Arabidopsis growth. Science 294(5543):846-849

Obel N, Erben V, Schwarz T, Kühnel S, Fodor A, Pauly M (2009) Microanalysis of plant cell wall polysaccharides. Mol Plant 2(5):922-932

Osato Y, Yokoyama R, Nishitani K (2006) A principal role for AtXTH18 in Arabidopsis thaliana root growth: a functional analysis using RNAi plants. J Plant Res 119(2):153-162

Pauly M, Albersheim P, Darvill A, York WS (1999a) Molecular domains of the cellulose/xyloglucan network in the cell walls of higher plants. Plant J 20(6):629-639

Pauly M, Andersen LN, Kaupinen S, Kofod LV, York WS, Albersheim P, Darvill A (1999b) A xyloglucan-specific endo$\beta$-1, 4-glucanase from Aspergillus aculeatus: expression cloning in yeast, purification and characterization of the recombinant enzyme. Glycobiology 9(1):93-100

Pauly M, Eberhard S, Albersheim P, Darvill A, York WS (2001a) Effects of the murl mutation on xyloglucans produced by suspension-cultured Arabidopsis thaliana cells. Planta 214(1): 67-74

Pauly M, Qin Q, Greene H, Albersheim P, Darvill A, York WS (2001b) Changes in the structure of xyloglucan during cell elongation. Planta 212(5-6):842-850

Perrin RM, Jia ZH, Wagner TA, O'Neill MA, Sarria R, York WS, Raikhel NV, Keegstra K (2003) Analysis of xyloglucan fucosylation in Arabidopsis. Plant Physiol 132(2):768-778

Puhlmann J, Bucheli E, Swain MJ, Dunning N, Albersheim P, Darvill AG, Hahn MG (1994) Generation of monoclonal antibodies against plant cell-wall polysaccharides. I. Characterization of a monoclonal antibody to a terminal $\alpha-(1 \rightarrow 2)$-linked fucosylcontaining epitope. Plant Physiol 104(2):699-710

Reiter WD, Chapple CCS, Somerville CR (1993) Altered growth and cell-walls in a fucose-deficient mutant of Arabidopsis. Science 261(5124):1032-1035

Reiter WD, Chapple CCS, Somerville CR (1997) Mutants of Arabidopsis thaliana with altered cell wall polysaccharide composition. Plant J 12(2):335-345

Sampedro J, Sieiro C, Revilla G, González-Villa T, Zarra I (2001) Cloning and expression pattern of a gene encoding an $\alpha$-xylosidase active against xyloglucan oligosaccharides from Arabidopsis. Plant Physiol 126(2):910-920

Sampedro J, Pardo B, Gianzo C, Guitián E, Revilla G, Zarra I (2010) Lack of $\alpha$-xylosidase activity in Arabidopsis alters xyloglucan composition and results in growth defects. Plant Physiol 154(3):1105-1115

Scheible WR, Pauly M (2004) Glycosyltransferases and cell wall biosynthesis: novel players and insights. Curr Opin Plant Biol 7(3):285-295

Scheller HV, Ulvskov P (2010) Hemicelluloses. Annu Rev Plant Biol 61:263-289

Selvendran RR, March JF, Ring SG (1979) Determination of aldoses and uronic acid content of vegetable fiber. Anal Biochem 96(2):282-292

Sigrist CJA, Cerutti L, de Castro E, Langendijk-Genevaux PS, Bulliard V, Bairoch A, Hulo N (2010) PROSITE, a protein domain database for functional characterization and annotation. Nucleic Acids Res 38:D161-D166

Smith RC, Fry SC (1991) Endotransglycosylation of xyloglucans in plant cell suspension cultures. Biochem J 279:529-535

Steele NM, Fry SC (2000) Differences in catalytic properties between native isoenzymes of xyloglucan endotransglycosylase (XET). Phytochemistry 54(7):667-680

Takeda T, Furuta Y, Awano T, Mizuno K, Mitsuishi Y, Hayashi T (2002) Suppression and acceleration of cell elongation by integration of xyloglucans in pea stem segments. Proc Natl Acad Sci USA 99(13):9055-9060

Tamura K, Shimada T, Kondo M, Nishimura M, Hara-Nishimura I (2005) KATAMARI1/MURUS3 is a novel Golgi membrane protein that is required for endomembrane organization in Arabidopsis. Plant Cell 17(6):1764-1776

Tedman-Jones JD, Lei R, Jay F, Fabro G, Li XM, Reiter WD, Brearley C, Jones JDG (2008) Characterization of Arabidopsis mur3 mutations that result in constitutive activation of defence in petioles, but not leaves. Plant J 56(5):691-703

Vanzin GF, Madson M, Carpita NC, Raikhel NV, Keegstra K, Reiter WD (2002) The mur2 mutant of Arabidopsis thaliana lacks fucosylated xyloglucan because of a lesion in fucosyltransferase AtFUT1. Proc Natl Acad Sci USA 99(5):3340-3345

Vincken JP, York WS, Beldman G, Voragen AGJ (1997) Two general branching patterns of xyloglucan, XXXG and XXGG. Plant Physiol 114(1):9-13

Vissenberg K, Fry SC, Pauly M, Höfte H, Verbelen JP (2005) XTH acts at the microfibril-matrix interface during cell elongation. J Exp Bot 56(412):673-683

Weigel D, Glazebrook J (2002) Arabidopsis: a laboratory manual. Cold Spring Harbor Laboratory Press, Cold Spring Harbor

Winter D, Vinegar B, Nahal H, Ammar R, Wilson GV, Provart NJ (2007) An "Electronic Fluorescent Pictograph" browser for exploring and analyzing large-scale biological data sets. PLoS One 2:8

York WS, Darvill AG, Albersheim P (1984) Inhibition of 2,4-dichlorphenoxyacetic acid-stimulated elongation of pea stem segments by a xyloglucan oligosaccharide. Plant Physiol 75(2):295-297

York WS, Darvill AG, McNeil M, Albersheim P (1985) 3-deoxyD-manno-2-octulosonic acid (KDO) is a component of rhamnogalacturonan-II, a pectic polysaccharide in the primary-cell walls of plants. Carbohydr Res 138(1):109-126

Zablackis E, Huang J, Muller B, Darvill AG, Albersheim P (1995) Characterization of the cell wall polysaccharides of Arabidopsis thaliana leaves. Plant Physiol 107(4):1129-1138

Zablackis E, York WS, Pauly M, Hantus S, Reiter WD, Chapple CCS, Albersheim P, Darvill A (1996) Substitution of L-fucose by Lgalactose in cell walls of Arabidopsis murl. Science 272(5269): $1808-1810$

Zabotina OA, WTGvd Ven, Freshour G, Drakakaki G, Cavalier D, Mouille G, Hahn MG, Keegstra K, Raikhel NV (2008) Arabidopsis XXT5 gene encodes a putative a-1, 6-xylosyltransferase that is involved in xyloglucan biosynthesis. Plant $\mathbf{J}$ 56(1):101-115

Zhou Q, Rutland MW, Teeri TT, Brumer H (2007) Xyloglucan in cellulose modification. Cellulose 14(6):625-641 